\title{
Surgical Management of Single and Multiple Brain Metastases: Results of a Retrospective Study
}

\author{
G. Schackert A. Steinmetz U. Meier S.B. Sobottka \\ Klinik und Poliklinik für Neurochirurgie, Universitätsklinikum Carl Gustav Carus, Technische Universität Dresden
}

Key Words

Brain metastasis · Surgery · Neuronavigation · Adjuvant radiotherapy

\section{Summary}

Background: Advancement in diagnosis and treatment of various cancer entities led to an increasing incidence of brain metastases in the last decades. Surgical excision of single and multiple brain metastases is one of the central treatment options beside radiotherapy, radiosurgery and chemotherapy. To evaluate the benefit of surgery with/without whole-brain radiation therapy (WBRT) in single brain metastases and the influence of image guidance for brain metastases resection, 104 patients were retrospectively evaluated for post-operative outcome. Patients and Methods: Between J anuary 1994 and December 1999150 patients were surgically treated for brain metastases at the Department of Neurosurgery at theTechnical University of Dresden. Outcome could be evaluated in 104 patients with respect to special treatment strategies and survival time (69 patients with single and 35 patients with multiple lesions). Results: Most metastases originated from primary lung and breast tumours. Karnofsky performance score improved on average by 10 after surgery. The extent of the extracerebral tumour burden was the main influence on survival time. Patients' age below 70 years was combined with prolonged survival time (median survival time, MST: 4.5 months vs. 7 months). Patients with solitary cerebral metastasis had a MST of 16 months, whereas patients with singular lesions has a MST of 7 and 4 months, depending on the extent of the extracerebral tumour growth. Additional post-operativeWBRT with $30 \mathrm{~Gy}$ was combined with an increase in MST in patients with single brain metastasis (surgery +WBRT: MST 13 months; surgery only: MST 8 months). In addition, the rate of recurrent cerebral tumour growth was distinctly higher in the non-WBRT group. Neuronavigation did not significantly improve post-operative survival time. In $80 \%$ of patients extracerebral tumour growth limited patients' survival. Conclusion: Surgery is an initial treatment option in patients with single and multiple brain metastases especially with large tumours $(>3 \mathrm{~cm})$. Post-operative WBRT seems to prolong survival time in patients with single brain metastasis by decreasing local and distant tumour recurrence. Neuronavigational devices permit a targeted approach. Multiple processes can be extirpated in one session without prolonging the hospitalisation time for the patient. However, neuronavigational devices cannot assure complete tumour resection.
Schlüsselwörter

Hirnmetastasen · Operation · Neuronavigation · Adjuvante Strahlentherapie

\section{Zusammenfassung}

Hintergnund: Fortschritte in der Diagnostik und Therapie von Krebserkrankungen haben in den letzten J ahrzehnten zu einer steigenden Inzidenz von Hirnmetastasen geführt. Die chirurgische Entfernung singulärer und multipler Hirnmetastasen stellt neben Strahlentherapie, Radiochirurgie und Chemotherapie eine zentraleTherapieoption dar. Um die Wertigkeit der chirurgischen Behandlung von singulären Hirnmetastasen mit/ohne Ganzhirnbestrahlung (WBRT) und den Einfluss der Neuronavigation zu untersuchen, wurden 104 Patienten retrospektiv bezüglich ihres postoperativen «Outcomes» untersucht. Patienten und Methoden: Zwischen J anuar 1994 und Dezember 1999 wurden 150 Patienten mit Hirnmetastasen in der Klinik für Neurochirurgie der Technischen Universität Dresden operiert. Das «Outcome» von 104 Patienten konnte bezüglich der verschiedenen Behandlungsstrategien und Überlebenszeit ausgewertet werden (69 Patienten mit singulären und 35 Patienten mit multiplen Läsionen). Ergebnisse: Die meisten Metastasen stammen von Lungen- und Mammakarzinomen. Nach operativer Behandlung verbesserte sich der Karnofsky-Index um durchschnittlich 10. Das Ausmaß der extrazerebralen Tumormasse stellte die Haupteinflussgröße für die Überlebenszeit dar. Ein Lebensalter unter $70 \mathrm{~J}$ ahren war mit einer verlängerten Überlebenszeit verbunden (mittlere Überlebenszeit, MÜZ: 4,5 Monate vs. 7 Monate). Patienten mit solitären Metastasen hatten eine MÜZ von 16 Monaten, während Patienten mit singulären Läsionen, abhängig vom Ausmaß des extrazerebralen Tumorwachstums, eine MÜZ von 7 bzw. 4 Monaten aufweisen. Eine zusätzliche postoperative WBRT mit 30 Gy zeigte eine Verbesserung der MÜZ bei Patienten mit singulären Hirnmetastasen (OP + WBRT: MÜZ 13 Monate; OP allein: MÜZ 8 Monate). Gleichzeitig war die Rate der zerebralen Tumorrezidive in der Nicht-WBRT Gruppe deutlich höher. Die postoperative Überlebenszeit wurde durch Verwendung der Neuronavigation nicht signifikant verbessert. In $80 \%$ der Patienten limitierte das extrazerebrale Tumorwachstum die Überlebenszeit. Fazit: Bei Patienten mit singulären und multiplen Metastasen stellt die initiale chirurgische Tumorentfernung eine Therapiealternative insbesondere bei großen Tumoren $(>3 \mathrm{~cm})$ dar. Eine postoperative WBRT scheint die ÜLZ der Patienten mit singulären Hirnmetastasen durch Begrenzung des Auftretens von Rezidivtumoren zu verlängern. Die Neuronavigation erlaubt eine gezielte Zugangsplanung. Multiple Prozesse können einzeitig operiert werden, ohne dass die postoperative stationäre Verweildauer verlängert wird. Hingegen wird eine radikale Tumorentfernung durch Verwendung der Neuronavigation nicht gewährleistet.

\begin{tabular}{ll}
\hline KARGER & ○ 2001 S. K arger G mbH , Freiburg \\
Fax +497614520714 & A ccessible online at: \\
$\begin{array}{l}\text { E-mail Information@K arger.de } \\
\text { www.karger.com }\end{array}$ & www.karger.com/journals/onk
\end{tabular}

\section{KARGER}

www.karger.com

\section{A ccessible online at:
www.karger.com/journals/onk}

Prof. D r. med. Gabriele Schackert

K linik und Poliklinik für Neurochirurgie, U niversitätsklinikum Carl G ustav Carus

Technische U niversität D resden

Fetscherstraße 74, D-01307 D resden (G ermany)

Tel. +49 351 458-2886, Fax - 4304 


\section{Introduction}

Cerebral metastases comprise more than $30 \%$ of brain tumours [1-3]. They occur in $30-40 \%$ of all cancer patients. M ost brain metastases originate from primary lung cancer (35\%) and breast cancer ( $21 \%$ ). A t the time of diagnosis more than $50 \%$ of the patients already have multiple lesions. In recent years brain metastases have been diagnosed more frequently because of the increasing life-span of people, the advancement in diagnostic tools and the optimised treatment of cancer patients which gives brain metastases more time to develop [4].

Generally, the occurrence of brain metastases is associated with the final stage of the metastasising process. A t this stage life expectancy is very limited. Therefore the goal in treating patients is to eliminate the life-threatening brain lesion while maintaining or optimising quality of life. To date, there are several therapy modalities available to treat these patients They range from surgical procedures, over radiosurgery, radiotherapy and chemotherapy to supportive care alone [5-8]. Selection of the appropriate treatment strategy for an individual patient can be difficult. Several prognostic factors have been stressed to mainly influence the survival time of the patients: control of the primary tumour, extent of extracerebral metastases, time interval between diagnosis of the primary tumour and the development of the cerebral lesions, number of cerebral lesions, K arnofsky performance scale score and age [9-14].

A fter operative treatment the median survival time of patients with a single lesion averages about 1 year, and in patients with multiple lesions it is about $6-12$ months $[8,12,14-16]$. Surgical treatment of brain metastases is usually followed by post-operative whole-brain radiation therapy (WBRT) with 30-40 G y. Surgery plus WBRT is superior to W BRT alone $[17,18]$. H owever, it is still controversial as to whether WBRT is necessary after complete extirpation of a single brain metastasis. In 1998, a first prospective randomised multicentre trial was published evaluating surgery only vs. surgery plus WBRT in patients with single brain metastasis [19]. The results demonstrate that patients treated with surgery alone have significantly more local and distant recurrences than those receiving surgery plus WBRT. The overall survival time and the length of time patients stayed functionally independent showed, however, no significant differences.

In the last few decades neurosurgical procedures have been optimised by technical advances, e.g. intra-operative ultrasound, neuronavigation, intra-operative magnetic resonance imaging and brain mapping. O perative extirpation of small, deep-seated or multiple lesions has become possible without increasing the risk of worsening patients' quality of life. The exact planning of the operative approach by computer simulation offers a safe and reproducible method. Multiple lesions can be operated on in one session, avoiding a prolongation of hospitalisation time [20-22].

The aim of this retrospective study was to evaluate different treatment strategies and the survival time of patients treated during the last few years for a single or multiple brain metastases at our institution. The study explored two questions:

i) How did postoperative WBRT in patients with a single brain metastasis influence outcome and survival time? ii) Do intra-operative technical advances, e.g. neuronavigational devices, lead to a prolonged survival time of patients with single and multiple cerebral metastases?

\section{Patients and Methods}

From January 1994 until December 1999, 150 patients with brain metastases were operated on at the Department of Neurosurgery, Technical $U$ niversity of $D$ resden. The patients were divided into two groups:

G roup 1: Patients with a single brain metastasis.

G roup 2: Patients with multiple brain metastases.

For the retrospective study a questionnaire was designed. Patients' data were evaluated with respect to different treatment strategies and survival time. The following factors were taken into consideration: origin of the primary tumour, time interval between the primary tumour and the development of cerebral lesions, extent of extra-cerebral tumour burden, number of cerebral lesions, surgery with neuronavigational devices, adjuvant radiation therapy and age. Q uality of life was assessed by using the $\mathrm{K}$ arnofsky performance score. Extra-cerebral tumour progression was defined in three stages:

i) Lack of extra-cerebral disease

ii) Stable disease

iii) Progressive disease

Lack of extra-cerebral disease was defined as no extra-cerebral tumour growth, either at the primary site or in other organs. Stable disease included patients with tumour growth at the primary site, but without extracerebral metastases. Progressive disease included patients with tumour growth at the primary site and metastases to other extra-cerebral organs. Statistical analysis was performed using the SPSS software program. $\mathrm{K}$ aplan-M eier survival analysis was applied to obtain survival rates. M ultivariate Cox regression and discriminant analysis were calculated to identify additional factors.

Surgical Procedure for Patients with Single and M ultiple B rain M etastases The cerebral lesions were diagnosed by magnetic resonance imaging (M RI). Cortical lesions were approached by using anatomical landmarks to plan the osteoplastic trephination. For extirpation of multiple or deepseated cerebral metastases the operation was planned pre-operatively using computers with neuronavigational devices. A fter application of fiducials on the patient's scalp an MRI volume scan in a thickness of 1 to $2 \mathrm{~mm}$ was performed. The two-dimensional data were transferred to computer three-dimensional imaging. The calculated data made it possible to visualise the tumours through the scalp, skull and brain surface (fig. 1). Computer imaging enabled us to plan the surgical approach by avoiding additional iatrogenic neurological deficits. Multiple lesions could be extirpated in one session by performing small craniotomies at different sites of the skull.

\section{Results}

O ut of 150 patients, 104 responded to the questionnaire. $69 \mathrm{pa}$ tients had suffered from a single brain metastasis and 35 from multiple lesions. In single brain metastasis, 35 patients were male, 34 patients female. In multiple lesions, 20 patients were male, 15 patients female.

\section{Distribution of the Primary Tumour Site and L ocation of the} Cerebral M etastasis

The distribution of the primary tumours is shown in figure $2.1 \mathrm{n}$ patients with a single brain metastasis the lung was the organ of origin for $24 \%$, the breast for $19 \%$, unknown primaries for $13 \%$, colon and kidney for $12 \%$ each and malignant melanoma 


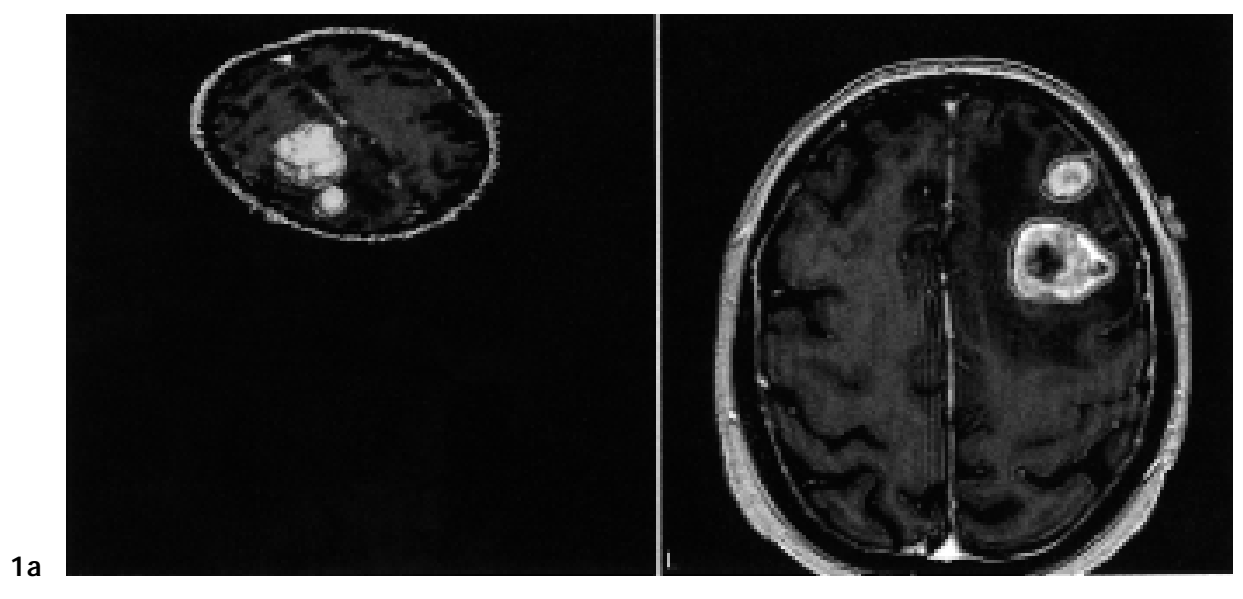

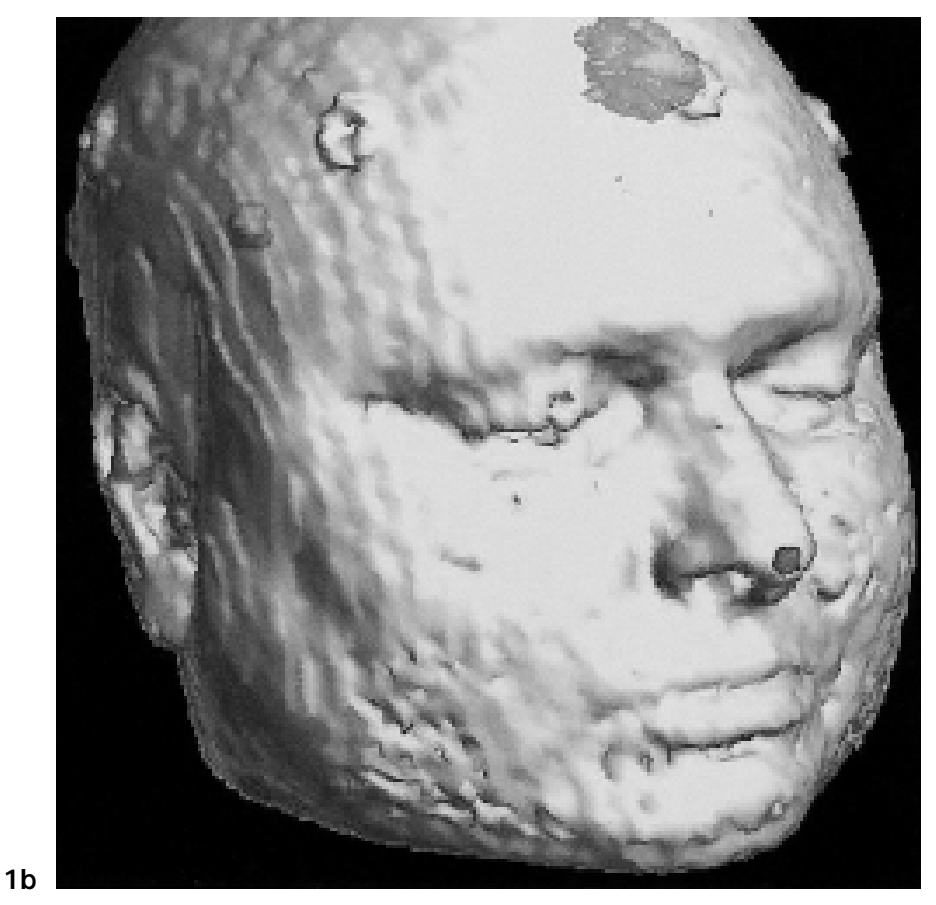

Fig. 1 a A xial T 1-weighted M R I after gadolinium showing two left frontal cerebral metastases. On the right side of the figure the tumour borders were marked. On the left side the tumour is visualised by a 3D surface rendering process. $\mathbf{b} 3 \mathrm{D}$ reconstruction of the head surface of a patient with multiple brain metastases. The tumour contours are visualised through the scalp.

for $10 \%$. In multiple cerebral lesions (fig. 2) the organ distribution again demonstrated a preference for the lung and breast with $21 \%$ and $16 \%$ respectively followed by the primary colon, malignant melanoma and unknown primaries with $13 \%$ each, the kidney with $6 \%$ and finally an equal distribution of $3 \%$ for the ovaries, cervix, bladder, thyroid, testis and oesophagus.

Most cerebral metastases were located in the frontal lobe, followed by the parietal, occipital, temporal lobe and the cerebellum in declining frequency (fig. 3 ).

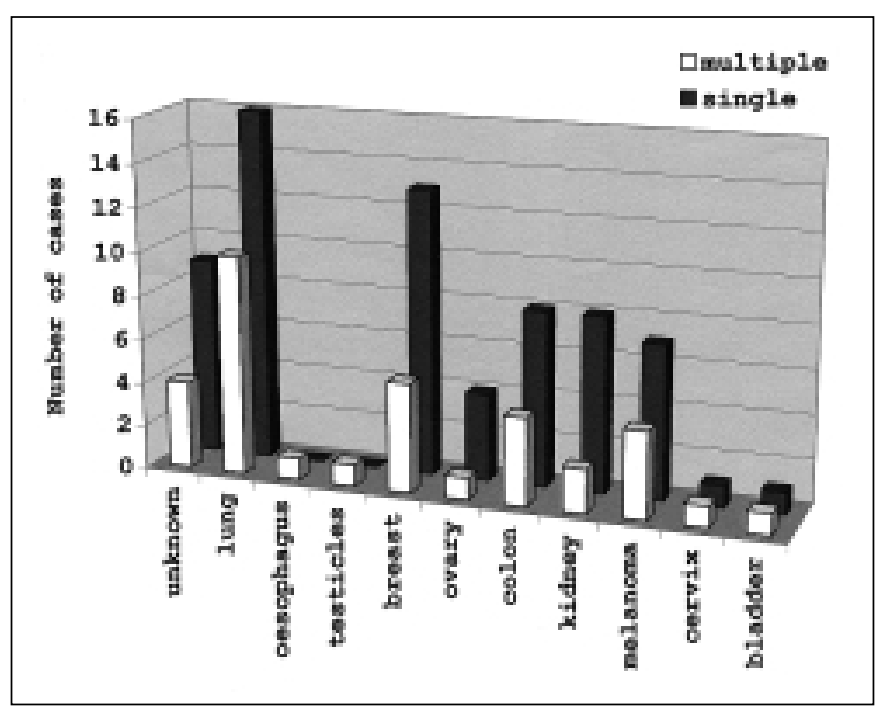

Fig. 2. Distribution of the primary tumour site of patients with single $(n=69)$ and multiple brain metastases $(n=35)$.

\section{A ge and Karnofsky Performance Score}

$M$ edian age was 61 years in patients with single brain metastasis and 58 years in those with multiple cerebral metastases. Patients older than 70 years of age had a median survival time of 4.5 months and patients under 70 years of age 7 months. The Karnofsky score averaged about 70 pre-operatively and 80 post-operatively in patients with single lesions. In patients with multiple tumours it averaged about 60 pre-operatively and 70 post-operatively. Four patients ( 2 with single and 2 with multiple lesions) suffered from post-operative complications: lung emboli, wound infection and progressive pulmonary metastases, post-operative haemorrhage and subdural empyema. The K arnofsky score dropped about $40-60$ points (table 1 ). The preoperative and post-operative $\mathrm{K}$ arnofsky scores of $>70$ and $>80$ respectively proved to be statistically significant with respect to survival time ( $p=0.023$ and $p=0.0001$ respectively) (fig. 4).

Cerebral M etastasis and Survival Time

The median survival time for patients with a single brain metastasis was 10 months and for those with multiple brain 


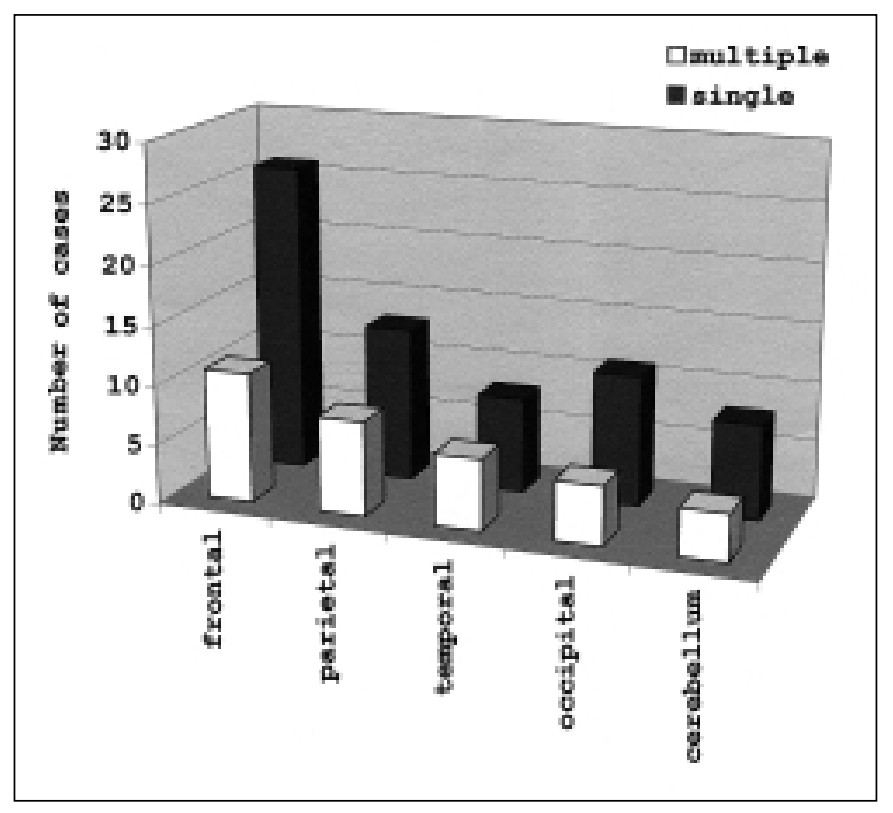

Fig. 3. R egional distribution of cerebral metastases in 69 patients with single and 35 patients with multiple brain metastases.

Table 1 Pre- and post-operative K arnofsky performance score and postoperative survival time of 4 patients with post-operative complications

\begin{tabular}{llll}
\hline Complications & $\begin{array}{l}\text { Preop. } \\
\text { KPS }\end{array}$ & $\begin{array}{l}\text { Postop. } \\
\text { KPS }\end{array}$ & $\begin{array}{l}\text { Survival } \\
\text { time, months }\end{array}$ \\
\hline $\begin{array}{l}\text { L ung emboli } \\
\text { Wound infection and progressive }\end{array}$ & 60 & 20 & 0 \\
$\quad$ pulmonary metastases & 80 & 20 & 2 \\
$\begin{array}{l}\text { Post-operative haemorrhage } \\
\text { Subdural empyema }\end{array}$ & 60 & 40 & 0 \\
& 80 & 40 & 1 \\
\hline
\end{tabular}

Preop. $\mathrm{K}$ PS $=$ Pre-operative $\mathrm{K}$ arnofsky performance score; Postop. K PS: post-operative $\mathrm{K}$ arnofsky performance score.

metastases 6 months ( $p=0.046$ ) (fig. 5). H owever, $20 \%$ of the patients with single lesions lived longer than 16 months, and $19 \%$ of the patients with multiple lesions survived more than 10 months. In patients with multiple lesions the number of cerebral metastases did not prove to be a relevant factor for survival time. In most of the tumours the time interval between the primary tumour and the development of cerebral metastasis was not found to be a significant factor for survival time. O nly in brain metastases of breast carcinoma the time interval showed a statistically significant influence on survival time $(p=0.020)$.

\section{Progress of Extra-Cerebral Tumour G rowth}

The progress of extra-cerebral tumour growth influenced the median survival time. Patients with a single brain metastasis but no extra-cerebral tumour growth showed a median survival time of 16 months, those with stable disease of 7 months and those with active tumour progress of only 4 months $(p=0.26)$ (fig. 6).
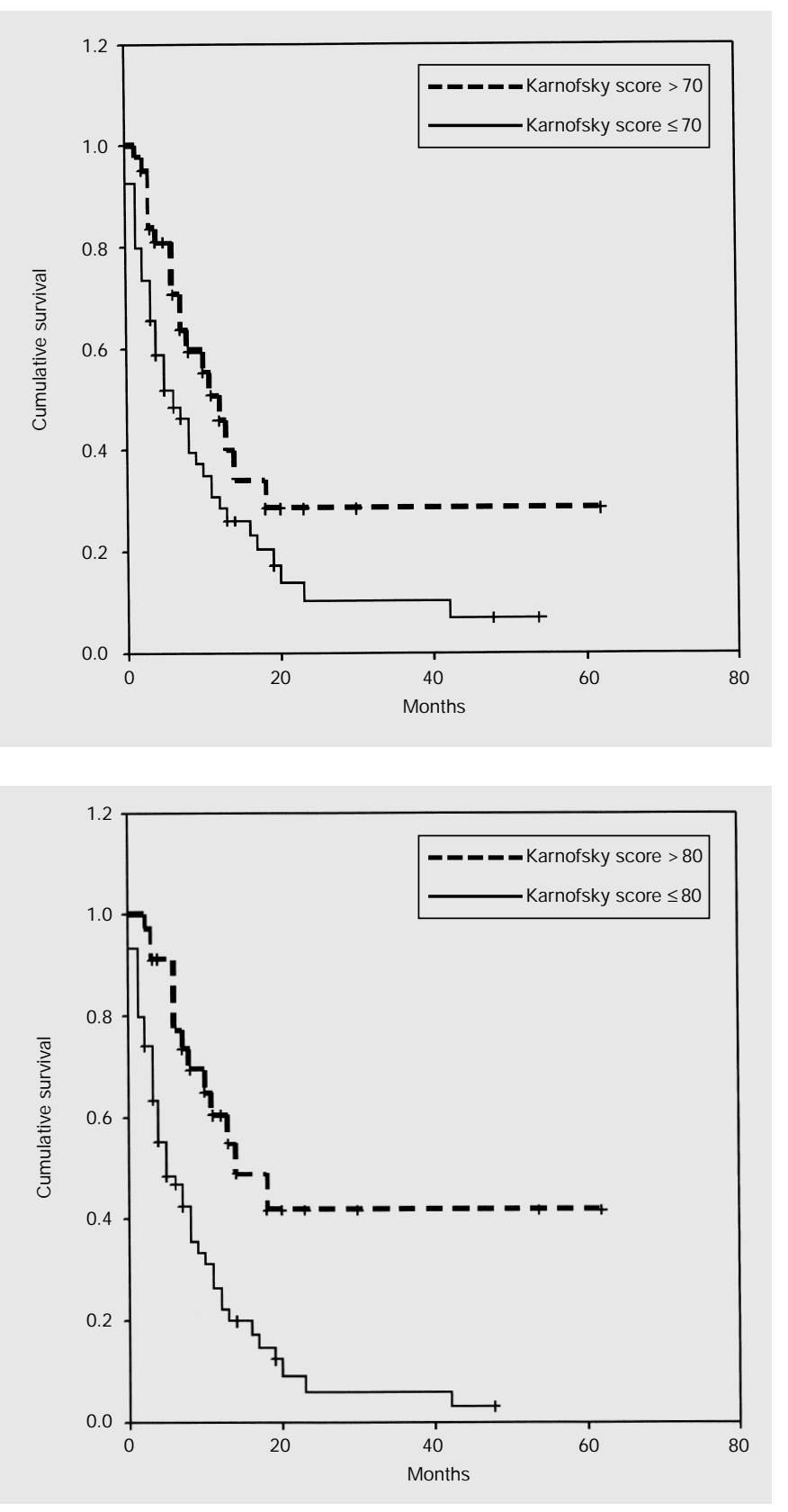

Fig. 4. a K aplan-M eier survival curve of patients with brain metastases depending on pre-operative $K$ arnofsky score ( $K$ arnofsky score $>70$, median survival time 12 months vs. $K$ arnofsky score $\leq 70$, median survival time $=$ 6 months) ( $p=0.023$ ) and b post-operative Karnofsky score (Karnofsy score $>80$, median survival time 14 months vs. Karnofsky score $\leq 80$, median survival time 5 months) ( $p=0.0001$ ).

In all patients with multiple lesions extra-cerebral tumour growth was apparent, involving two additional organs.

\section{N euronavigation}

N euronavigation as an operative technique was evaluated with respect to survival time in patients with single and multiple lesions. N euronavigation allows a targeted approach and was applied in patients in whom a conventional operative approach might be harmful. Median survival time was prolonged in 


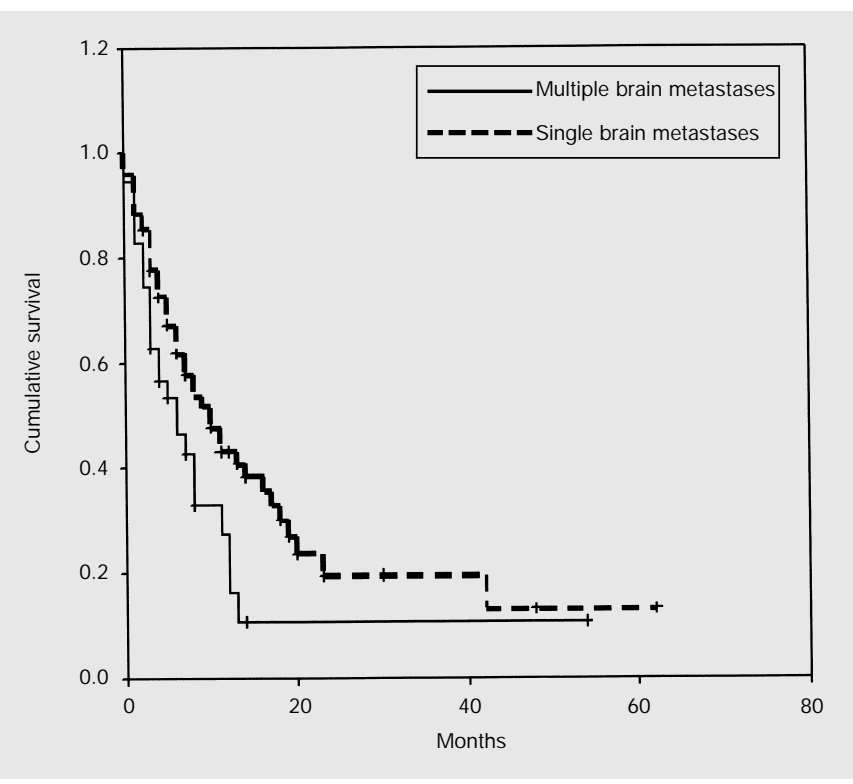

Fig. 5. Kaplan-M eier survival curve of patients with single (median survival time 10 months) and multiple brain metastases (median survival time 6 months) $(p=0.046)$.

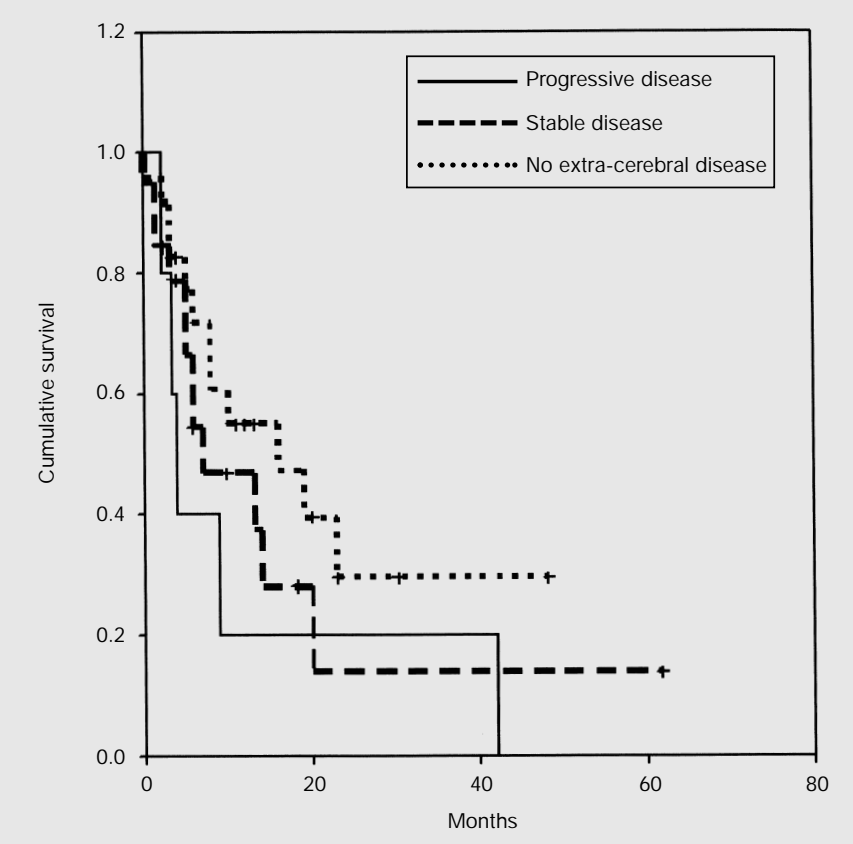

Fig. 6. Kaplan-M eier survival curve of patients with cerebral metastases with respect to extra-cerebral tumour growth (progressive disease, median survival time 4 months vs. stable disease, median survival time 7 months vs. no extra-cerebral disease, median survival time 16 months) $(p=0.26)$.

patients in whom neuronavigational devices were applied (16 months vs. 10 months in patients with a single metastasis, $p=0.76$; 11 months vs. 5 months in those with multiple lesions, $p=0.19$ ) (fig. 7). However, the results were statistically not significant.
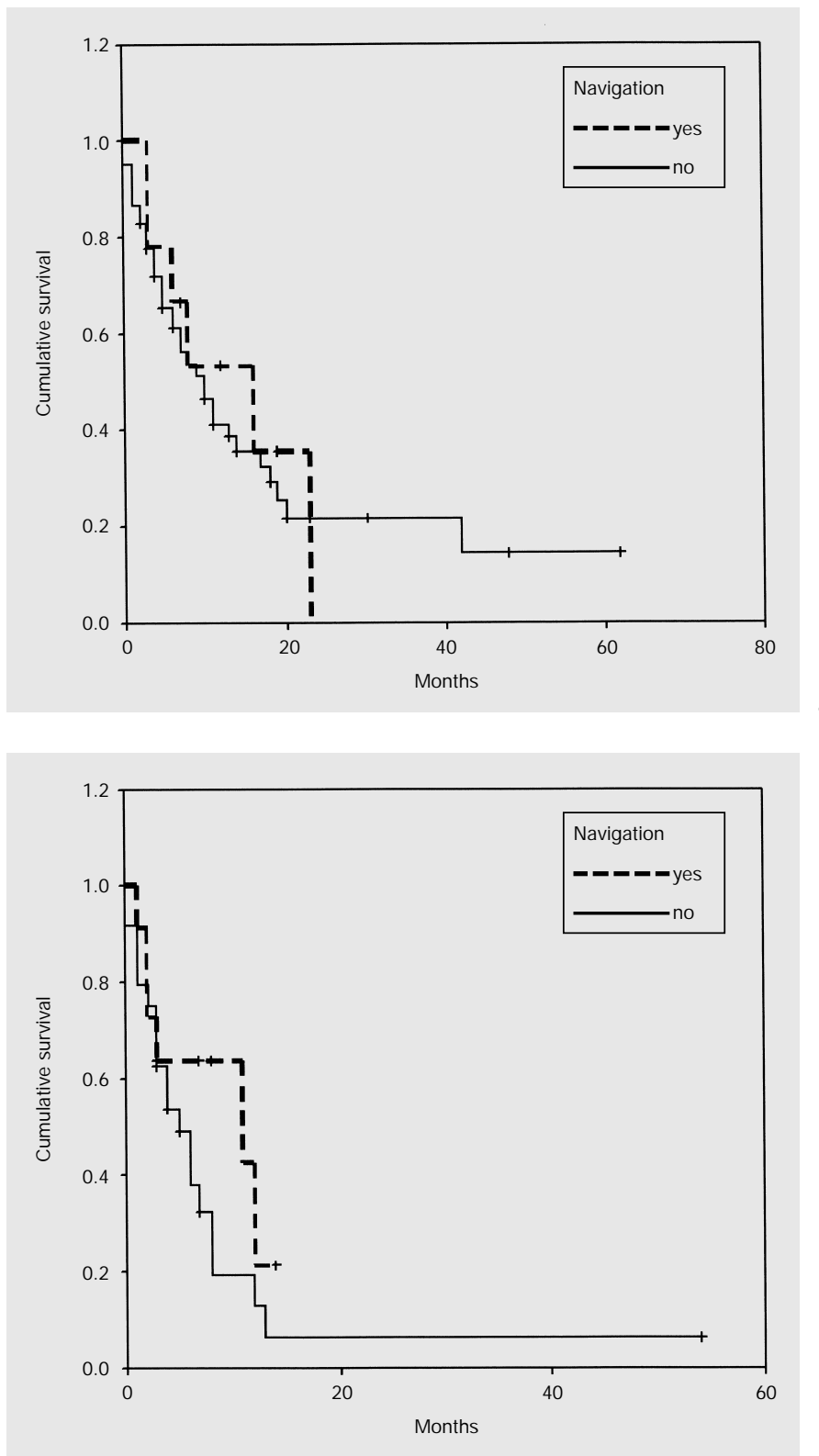

Fig. 7. $K$ aplan-M eier survival curve of patients undergoing surgical resection for cerebral metastases with and without neuronavigational guidance. a Patients with single lesions (with navigation, mean survival time 16 months vs. without navigation median survival time 10 months) $(p=0.76)$. b Patients with multiple lesions (with navigation, median survival time 11 months vs. without navigation, median survival time 5 months) $(p=0.19)$.

\section{Surgical Resection and WBRT}

28 patients with a single brain metastasis received surgery alone and 31 surgery plus adjuvantWBRT. The selection to one of both treatment groups was based on the intra-operative extent of tumour removal and post-operative CT scan. Patients with incomplete tumour removal were selected for adjuvant WBRT and patients with complete tumour removal for surgery only. In the group receiving surgery plus WBRT, the median survival averaged about 13 months, whereas in the surgical group median survival time was reduced to 8 months ( $p=0.15$ ) (fig. 8a). 


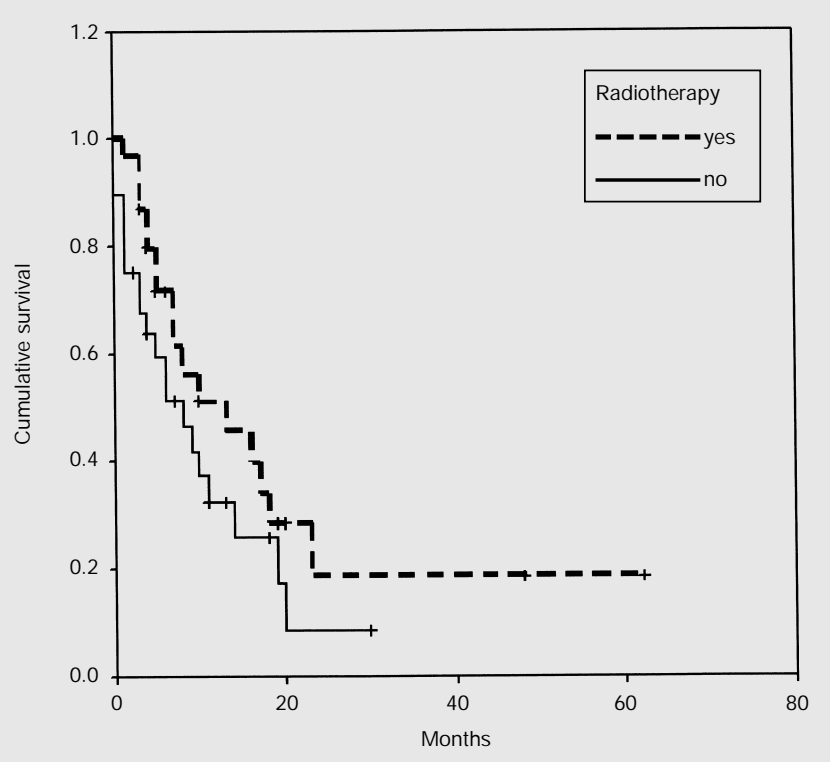

a

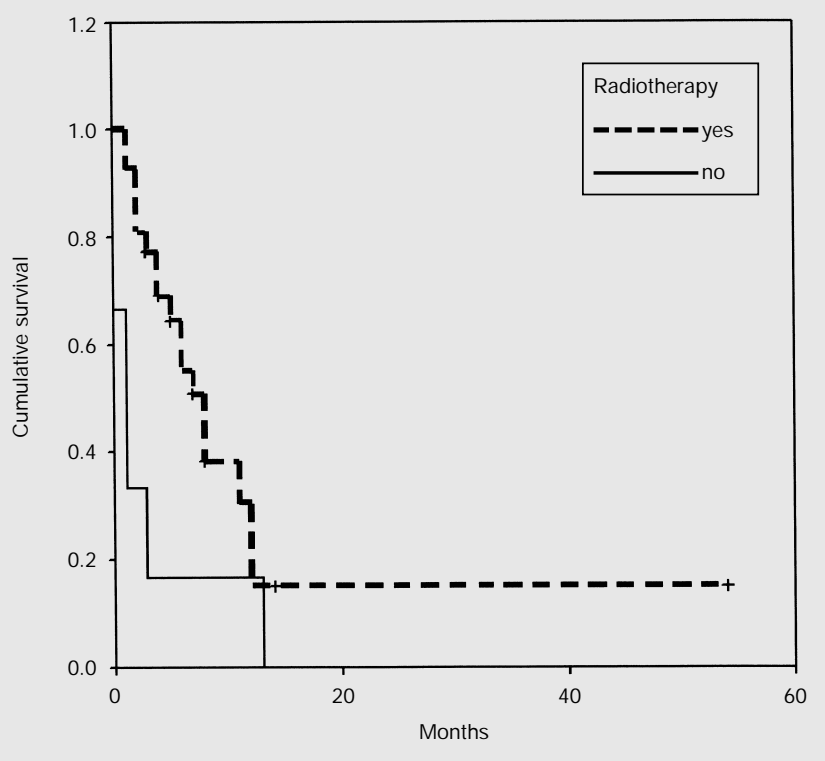

b

In multiple cerebral lesions post-operative radiotherapy was applied on a routine basis whenever possible. A II patients were treated with $30 \mathrm{G}$ y WBRT, receiving $1.5 \mathrm{G}$ y/day. In the treatment group receiving surgery plus radiotherapy the median survival time amounted to 8 months, and in 9 cases with surgery alone survival time was 1 month $(p=0.03)$ (fig. $8 b)$. In all cases with multiple cerebral metastases, extra-cerebral tumour burden was apparent, and metastatic seeding involved at least two additional extra-cerebral organs. The overall median survival time of both groups, multiple and single metastases, amounted to 8 months in the surgery plus WBRT group and 6 months in the surgery alone group ( $p=0.099$ ) (fig. $8 c$ ).

\section{Recurrence of Tumour G rowth}

In the group with post-operative radiation therapy, including patients with a single metastasis as well as those with multiple lesions, local recurrent tumour growth occurred in $13 \%$, distant

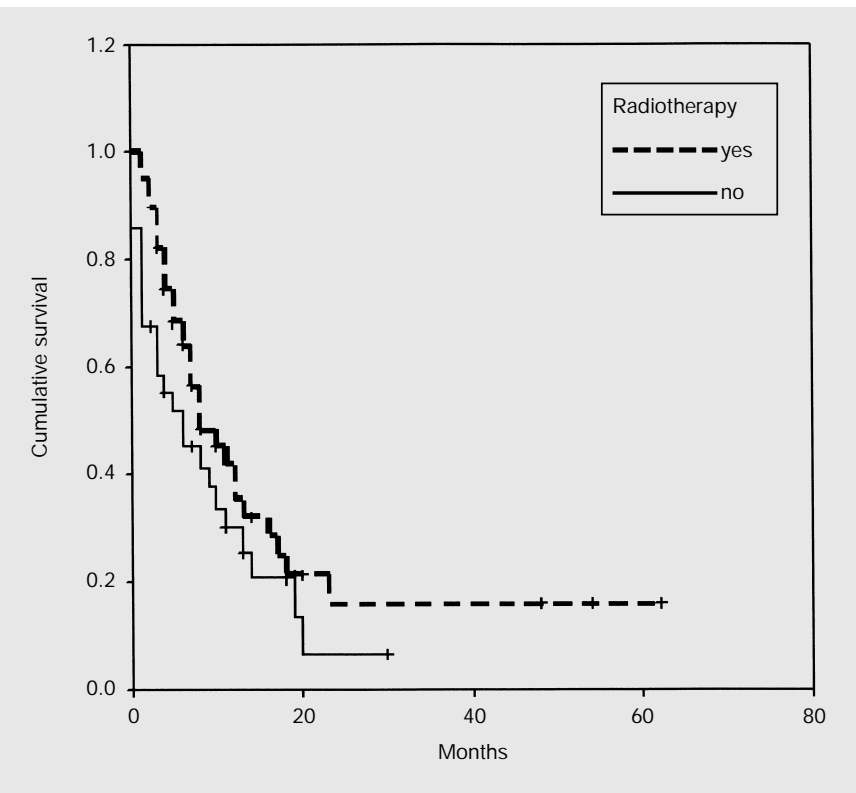

Fig. 8. Kaplan-M eier survival curve of patients with cerebral metastases with respect to post-operative radiotherapy. a Patients with single lesions (with radiotherapy, mean survival time, 13 months vs. without radiotherapy, median survival time 8 months) ( $p=0.15)$. b Patients with multiple lesions (with radiotherapy, median survival time 8 months vs. without radiotherapy, median survival time 1 months) $(p=0.03)$. c A II patients with cerebral metastases (with radiotherapy, median survival time 8 months vs. without radiotherapy, median survival time 6 months) $(p=0.099)$.

metastasis in $9 \%$ and local and distant metastases in $11 \%$ of the patients. $67 \%$ of the patients had no recurrent cerebral seeding. In patients not receiving post-operative radiotherapy, $22 \%$ developed local re-growth, $11 \%$ distant metastases and $14 \%$ both local re-growth and distant metastases. $53 \%$ of the patients did not develop recurrent cerebral tumour growth $(p=0.24)$ (fig. 9). 44 patients underwent surgery after tumour regrowth. Median interval to re-growth was 4.5 months. Median survival time after re-operation amounted to 6 months. Chemotherapy was not applied on a routine basis, and preoperative radio- or chemotherapy had no influence on postoperative survival (data not shown).

In $80 \%$ death was caused by the progression of extra-cerebral tumour growth. O nly in 20\% were cerebral metastases responsible for death.

\section{Discussion}

The prognosis of patients with cerebral metastases is poor. M edian survival time averages about 1 year, applying proven treatment modalities, including surgery, radiotherapy and chemotherapy. Several parameters have been identified as relevant factors for prognosis: control of the primary tumour, extent of extra-cerebral metastases, time interval between diagnosis of the primary tumour and development of cerebral lesions, number of cerebral lesions, K arnofsky performance scale score and age [9-14]. 

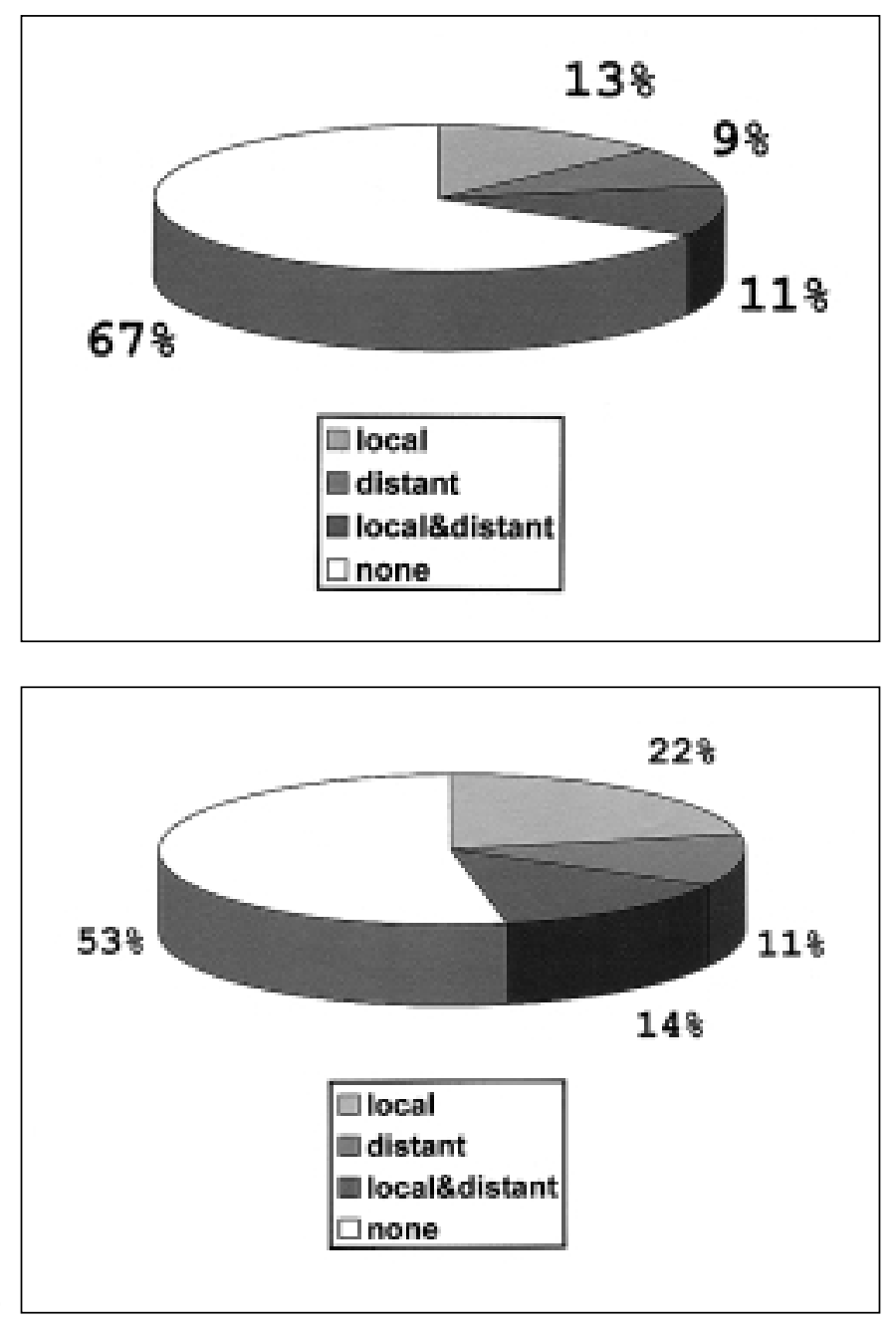

Fig. 9. a Frequency and location of recurrent tumour growth in patients with cerebral metastases after tumour resection and post-operative radiotherapy and $\mathbf{b}$ tumour resection only $(p=0.24)$.

Surgery is the treatment of choice for a single brain metastasis. L esions larger than $3 \mathrm{~cm}$ in diameter should be removed surgically whenever accessible as they lead to increased intracranial pressure. The decision to operate depends on the clinical status of the patient. Patients in good clinical condition with a K arnofsky performance scale score of 70 have been shown to profit from surgical intervention [11-13]. In our series the median $\mathrm{K}$ arnofsky score averaged about 70 in patients with a single brain metastasis and 60 in patients with multiple cerebral lesions. In both groups the K arnofsky score improved by about 10 points post-operatively. A pre-operative Karnofsky score $>70$ and a post-operative score $>80$ was demonstrated to be a significant factor for prolongation of the survival time. In 4 patients post-operative complications occurred, reducing the $\mathrm{K}$ arnofsky score by about $40-60$ points. In these cases the patients' survival time was mainly influenced by the complication. A s age is known to be a relevant factor for outcome, this was also evaluated in our group. Patients under 60 years of age have a better prognosis than those over 60 years [14]. The median age of our patients amounted to 61 years for patients with single brain metastasis and 58 years for those with mul- tiple metastases. Patients older than 70 years of age had a survival time of only 4.5 months compared to patients under 70 years of age who survived 7 months. The major reason for the diminished life expectancy was multimorbidity and therefore a reduction in the compensatory capacity of the patients. The decision to conduct operative treatment should depend on the biological age of the patient. A ctive treatment strategies are also justified in older patients who are still young biologically and who do not suffer from other diseases.

Patients with solitary lesions have the best prognosis of all patients suffering from brain metastases. In these patients the primary tumour should be under control and extra-cerebral metastases are absent. A ccording to recent publications, the median survival time ranges between 12 and 18 months [13-17, 23]. It is known that in cases of solitary brain lesions surgical removal of the cerebral lesion can even lead to a long-term survival of more than 10 years [24, 25]. In our series patients with solitary cerebral lesions had a median survival time of 16 months. Some of them, however, were long-term survivors who lived more than 4 years. In all patients whole-body tumour staging was performed. No extra-cerebral tumour growth was apparent. One of the obvious problems in defining patients with a solitary metastasis is the unknown number of those who have undetected extra-cerebral tumour growth. Extra-cerebral metastases influence survival time significantly. In our study we distinguished between patients without systemic disease, with stable extra-cerebral tumour burden and with progressive disease. Patients without systemic disease had the best prognosis (a median survival time of 16 months). Patients with stable disease showed a median survival time of 7 months, whereas progressive extra-cerebral tumour disease reduced the median survival time to 4 months. Smalley et al. [15] reported on 229 patients with a solitary or singular brain metastasis. Patients without systemic disease and total extirpation of the metastatic lesion had a median survival time of 1.3 years, whereas patients with systemic disease and subtotal removal of the brain tumour survived only 5.3 months. Besides the amount of extra-cerebral tumour burden, the extent of tumour resection is another important prognostic factor. It has been confirmed by several publications that incomplete tumour resection reduces survival time significantly $[15,26]$. In order to determine whether a brain metastasis has been removed completely or not, it should be mandatory to evaluate all patients post-operatively by an M RI scan with contrast media within the first $48 \mathrm{~h}$. A lbert et al. [27] demonstrated that intra-parenchymal tumour residues leading to a disruption of the bloodbrain barrier can be discovered post-operatively by early contrast-enhanced MRI. The investigation has to be performed within the first $48 \mathrm{~h}$ after tumour removal. Contrast enhancement at the tumour margins is suggestive of remaining tumour. M R I scans performed at a later time may already present with marginal enhancement at the resection cavity caused by the beginning of the repair process. In our study 31 patients with a single brain metastasis received post-operative WBRT, applying $30 \mathrm{G}$ y (median survival time 13 months), whereas 28 patients did not (median survival time 8 months). The selection criteria for adjuvant WBRT was the extent of intra-operative tumour removal. Patients in whom tumour removal was incomplete received adjuvant radiotherapy post-operatively. 
H owever, the extent of tumour removal was not confirmed by early post-operative M RI scan. A s mentioned above, there is still no agreement as to whether patients with a single brain metastasis should be irradiated post-operatively or not. Considering the fact that brain metastases are usually well circumscribed and grow less invasive than primary brain tumours, complete tumour removal may be sufficient to avoid local regrowth. Statistical analysis of our patients revealed that patients with post-operative WBRT developed fewer local or distant cerebral metastases than those without WBRT even though the radiation group was supposed to have incomplete surgical tumour removal. 0 ur groups were too small to reach statistical significance. Evidence that post-operative WBRT reduces cerebral recurrent tumour growth has been published by others [28]. The randomised prospective trial by Patchell et al. [19] comparing surgery vs. surgery plus radiotherapy confirms the relevance of post-operative radiotherapy. In this study all patients were evaluated post-operatively by MRI scan. Complete tumour removal was assured. A djuvant WBRT prevented recurrent tumour growth with statistical significance although the overall survival time could not be prolonged. $O$ ne has to keep in mind not only that tumour cells might be left at the operation site causing local re-growth but also that, considering the process of metastasising, small tumour cell clumbs not visible by MRI have already seeded and start dividing. These initial tumours might be destroyed by WBRT.

Correlation of survival time to organ distribution of the primary tumours demonstrates a significant relationship between these two parameters only in case of brain metastases from primary breast tumour. A significant parameter in survival time after diagnosis of a brain metastasis is the time interval between manifestation of the primary tumour and onset of the first symptoms of the cerebral lesion [11]. E specially in breast carcinoma, the time interval between the primary tumour and brain metastasis can take years. In our series, patients with breast carcinoma and in some cases with malignant melanoma also demonstrated the longest time interval, ranging between 4 and 13 years. In these cases the time interval between the primary tumour and the development of the cerebral metastasis correlated with prolonged survival time. However, only for breast carcinoma a statistical significance was found. In an analysis of recently published studies evaluating survival time of patients with surgically treated brain metastases from different primaries (colon carcinoma [10], non-small cell lung cancer [14], renal carcinoma [29], breast carcinoma [23], malignant melanoma [13]), no significant difference in patient's outcome was obvious. Only breast carcinoma patients with tumours that were hormone receptor-positive had significantly longer survival times than those with tumours that were hormone receptor-negative ( 21.9 months vs. 12.5 months) [30].

There is an indication for re-operation if the time interval between the first cerebral metastasisand recurrent tumour growth is longer than 4 months and the patient has a Karnofsky score of more than 60 [31, 32]. Patients can profit from surgical management in cases of recurrent tumour growth. In the publication by $B$ indal et al. [32] median survival time ranged about 11.5 months. In our series 44 patients had tumour re-growth. M edian interval to re-growth was 4.5 months. M edian survival time after re-operation amounted to 6 months.
Surgical treatment of multiple brain metastases is still a matter of debate. The detection of a certain number of brain metastases by MRI does not exclude others. Tumours at a very initial state might be undetected, even in T 2 or flare-weighted M R I sequences. The indication for active treatment strategies depends on the Karnofsky score, the extent of extra-cerebral tumour growth and the number of cerebral lesions. Multiple cerebral lesions can be treated by WBRT, by surgery or by radiosurgery $[5-8,18,33]$. A Iso supportive care only might be justified, especially in cases of reduced clinical conditions, e.g. K arnofsky score $<50$. R easons for surgical extirpation are large tumours with a diameter of more than $3 \mathrm{~cm}$, causing elevated intra-cranial pressure and the need for histological confirmation. In unknown primaries histological confirmation of the cerebral process has to be demanded.

Today, two treatment modalities are available to approach multiple brain metastases in a targeted manner: radiosurgery by linear accelerator or gamma knife and surgery [8, 12, 14, 20, $21,34-37]$. U $p$ to three cerebral lesions can be removed either by surgery or radiosurgery. For radiosurgery the diameter of the tumours should not exceed $3 \mathrm{~cm}$ [34, 35]. Technical advances in neurosurgery make it possible to operate on multiple cerebral lesions in one session. Neuronavigational devices allow for a targeted operative approach. M ultiple and deep-seated lesions can be extirpated without causing additional neurological deficits. With the aid of neuronavigation multiple brain metastases were removed in our series. 35 patients were operated on, and the number of extirpated lesions ranged between 2 and 4 . The tumours were removed in one session. M ost frequently patients suffered from primary lung, primary breast cancer, malignant melanoma or unknown primaries. When surgery was applied, post-operative complications only occurred in 2 patients causing the Karnofsky score to drop. No additional morbidity was caused in any of the other patients. Patients were sent home 8 days after the operation. Hospitalisation time was no longer than for patients with a single brain metastasis, and the median survival time of our patients amounted to 8 months. Post-operative WBRT was applied on a routine basis. When WBRT could not be performed, patients died within 1-3 months. Comparing the survival time of patients operated on with neuronavigation and those without, there was no statistically significant proIongation of survival time. The selection criteria we used for neuronavigation partially explains the result. N euronavigation was applied if the tumour was deep-seated or close to functionally important areas of the brain, and the surgeon was trying to avoid further deterioration as a result of the operative procedure. If the tumour could be reached without any problem, no neuronavigation was performed. The other point that must be considered is the limitation of neuronavigational devices. Neuronavigation is a safe tool for approaching cerebral lesions and avoiding additional neurological deficits, but it is not a tool for assuring complete extirpation of an intraparenchymal process. The problem involved relates to brain shift. Since during the operation the data available have been gathered pre-operatively, intra-operative brain shift caused by cerebrospinal fluid (CSF) loss, volume reduction by extirpation of the tumour or retraction of brain regions by spatulas cannot be calculated by the computer in real time. The only 
tool that can confirm complete extirpation of a tumour intraoperatively is intra-operative M R I [38].

A fter surgery or radiosurgery, the survival times of patients with multiple brain metastases are comparable and range between 6 and 12 months. R ecent publications have reported that patients with more than two lesions have a significantly worse prognosis than those with fewer than two lesions [35, 39]. In our series of patients with multiple lesions the number of cerebral metastases did not prove to be a significant factor for survival time.

O ur investigation showed that $80 \%$ of the patients died because of extra-cerebral tumour progress, whereas only $20 \%$ died of cerebral metastases. The results of recent retrospective studies and our own confirm that surgical management of single and multiple cerebral metastases is appropriate to relieve neurological symptoms and prolong the survival time of patients. H owever, as the course of the malignant cancer involves the whole body, the success of local therapeutic strategies is limited.

\section{Conclusion}

Surgery is one of the proven treatment modalities for patients with brain metastases. E specially large tumours $(>3 \mathrm{~cm})$ should be removed by surgical intervention.

Two main questions were addressed in our investigation:

i) The indication for post-operative adjuvant WBRT after extirpation of a single brain metastasis.

ii) The value of neuronavigational devices in extirpation of multiple brain lesions.

O ur results have demonstrated that post-operative WBRT subsequent to extirpation of a single brain metastasis may prolong the survival time of the patient. Local and distant tumour recurrence can be influenced, delayed or hindered. However, if statistical significance is to be found, our group must be enlarged.

Surgery is possible for single and multiple lesions. A Iso, small or deep-seated tumours can be approached by an operation, since neuronavigational devices permit a targeted approach and avoid additional iatrogenic deficits. M ultiple processes can be extirpated in one session without prolonging the hospitalisation time for the patient. However, neuronavigational devices cannot assure complete tumour resection. Therefore, no effect on the prolongation of survival time can be expected. $\mathrm{MRI}$ is the only adequate method of confirming complete tumour resection, but one still has to bear in mind the biological process of metastasising which involves the whole body and will always limit the success of regional treatment strategies.

\section{References}

1 Posner J B: M anagement of brain metastases. R ev Neurol (Paris) 1992;148:477-487.

2 Cairncross J G, Posner J $B$ : The management of brain metastases; in Walker MD (ed): O ncology of the Nervous System. B oston, Nijhoff, 1983, pp 341-377.

3 Takakura K, Sano K, H ojo S, H irano A : M etastatic Tumors of the Central Nervous System. Tokyo, I gaku-Shoin, 1982.

4 Patchell R A : B rain metastases; in B lack P, L oeffler J $S$ (eds): Cancer of the N ervous System, chapter 35. B oston, B lackwell Science, 1997, pp 653-663.

5 Galicich J, A rbit E: Metastatic brain tumors; in Youmans] (ed): N eurological surgery, 3rd ed. Philadelphia, Saunders, 1990, pp 3204-3222.

6 Patchell R A : Brain metastases. Neurol Clin 1991;9: 817-824.

7 Shu HKG, Sneed PK, Shiau CY, M CD ermott MW, Lamborn KR, Park E, Ho M, Petti PL, Smith V Verhey LI, Wara WM, Gutin PH, Larson DA Factors influencing survival after gamma knife radiosurgery for patients with single and multiple brain metastases. Cancer J Sci A m 1996;2:335

8 Bindal RK, Sawaya R, L eavens M E, L ee J J : Surgical treatment of multiple brain metastases. J N eurosurg 1993;79:210-216.

9 A ndrews RJ, G luck DS, Konchingeri RH: Surgical resection of brain metastases from lung cancer. A cta N eurochir (Wien) 1996;138:382-389.

$10 \mathrm{H}$ ammoud M A , M cCutcheon IE , Elsouki R, Schoppa $D$, Patt Y Z: Colorectal carcinoma and brain metastases: Distribution, treatment, and survival. Ann Surg O ncol 1996;3:453-463.

11 Lagerwaard FJ, L evendag PC, Nowak PJ, Eijkenboom W M , H anssens PE, Schmitz PI: I dentification of prognostic factors in patients with brain metastases: A review of 1,292 patients. Int J Radiat Oncol Biol Phys 1999;43:795-803.

12 Nussbaum ES, Djalilian HR, Cho KH, Hall WA: B rain metastases. Histology, multiplicity, surgery, and survival. Cancer 1996:78:1781-1788.

13 Sampson J H, Carter J H, Friedman A H, Seigler H F : Demographics, prognosis, and therapy in 702 patients with brain metastases from malignant melanoma.J Neurosurg 1998;88:11-20.

14 W ronski M , A rbit E, Burt M, G alicich J H : Survival after surgical treatment of brain metastases from lung cancer: A follow-up study of 231 patients treated between 1976 and 1991. J Neurosurg 1995; 83:605-616.

15 Smalley SR, Laws ER J r, O'Fallon JR, Shaw EG, Schray MF: R esection of solitary brain metastasis. J Neurosurg 1992;77:531-540.

16 Delarive J, deTribolet $\mathrm{N}$ : Cerebral metastases. A study of a surgical series of 81 cases. N eurochirurgie 1992;38:89-97.

17 Patchell RA, Tibbs PA, Walsh JW, Dempsey RJ, $M$ aruyama $Y, K$ ryscio RJ, M arkesbery WR, M acdonald $J$ S, Y oung $B: A$ randomized trial of surgery in the treatment of single metastases to the brain. N Engl J Med 1990;322:494-500.

18 Vermeulen SS: Whole brain radiotherapy in the treatment of metastatic brain tumors. Semin Surg Oncol 1998;14:64-69.

19 Patchell RA, Tibbs PA, Regine WF, Dempsey RJ, M ohiuddin $M$, K ryscio RJ, M arkesbery WR, Foon $K A$, Young $B$ : Postoperative radiotherapy in the treatment of single metastases to the brain: A randomized trial. JA M A 1998;280:1485-1489.
20 Sobottka SB, Steinmetz A , Schackert G : N euronavigation - the gentle way of removing brain tumours. Onkologie 1997;20:362-370.

21 Sobottka SB, Schackert G, Steinmetz A : Suitability and limitations of pointer-based and microscopebased neuronavigational systems for surgical treatment of intracerebral tumours - a comparative study of 66 patients. O nkologie 1998;21:137-142.

22 K ondziolka D, L unsford LD : Intraoperative navigation during resection of brain metastases. N eurosurg Clin N orth A m 1996;7:267-277.

23 W ronski M, A rbit E, M cCormick B: Surgical treatment of 70 patients with brain metastases from breast carcinoma. Cancer 1997;80:1746-1754.

24 Famell GF, B uckner J C, Cascino TL, O 'Connell MJ, Schomberg PJ, Suman V: Brain metastases from colorectal carcinoma. The long term survivor. Cancer 1996;78:711-716.

25 N ieder C, Walter K, N estle U, Schnabel K :Ten years disease-free survival after solitary brain metastasis from breast cancer. J Cancer Res Clin O ncol 1996; 1:169-178.

26 Stevens G, Firth I, Coates A : Cerebral metastases from malignant melanoma. Radiother Oncol 1992; 23:185-191.

27 A Ibert FK , Forsting M , Sartor K, A dams H P, Kunze $S$ : $E$ arly postoperative magnetic resonance imaging after resection of malignant glioma: O bjective evaluation of residual tumor and its influence on regrowth and prognosis. Neurosurgery 1994;34:45-60.

28 Skibber J M, Soong SJ , A ustin L, B alch CM , Sawaya $R E$ : Cranial irradiation after surgical excision of brain metastases in melanoma patients. A nn Surg Oncol 1996;2:118-123. 
29 Wronski M, A rbit E, R usso P, Galicich JH: Surgial resection of brain metastases from renal cell carcinoma in 50 patients. U rology 1996:47:187-193.

30 Pieper DR , H ess K R, Sawaya R E : R ole of surgery in the treatment of brain metastases in patients with reast cancer. A nn Surg O ncol 1997:4:481-490.

$31 \mathrm{~A}$ rbit $\mathrm{E}$, W ronski $M$, B urt $M$, G alicich J $H$ : The treatment of patients with recurrent brain metastases. $A$ retrospective analysis of 109 patients with non-smal cell lung cancer. Cancer 1995;76:765-773.

32 Bindal RK, Sawaya R, Leavens ME, Hess KR, Taylor SH: Reoperation for recurrent metastatic brain tumors. J Neurosurg 1995;83:600-604.

33 Weber F, Riedel A, Koning, M enzel J: The role of adjuvant radiation and multiple resection within the surgical management of brain metastases. Neurosurg R ev 1996;19:23-32.

$34 \mathrm{~K}$ ida Y, K obayashi T, Tanaka T: R adiosurgery of the metastatic brain tumors with gamma knife. A cta Neurochir Suppl (Wien) 1995;63:89-94.

35 A lexander E III, M oriatry TM, D avis R B, Wen PY, Fine HA, B lack PM , Kooy H M , L oeffler J S: Stereotactic radiosurgery for the definitive, noninvasive treatment of brain metastases. J Natl Cancer Inst 1995;87:34-40.

36 Breneman JC, Warnicke RE, A lbright RE, Kukiatinant N, Shaw J, A rmin D, Tew J J r: Stereotactic radiosurgery for the treatment of brain metastases. R esults of a single institution series. Cancer 1997;79:551-557.
37 M ehta MP, Rozental J M, L evin A B, M ackie TR Kubsad SS, G ehring MA, K insella TJ : D efining the role of radiosurgery in the management of brain metastases. Int J Radiat Oncol Biol Phys 1992;24 619-625.

38 Wirtz $C R, K$ nauth $M$, Staubert $A$, B onsanto $M M$, Sartor K, Kunze S, Tronnier V M : Clinical evaluation and follow-up results for intraoperative magnetic resonance imaging in neurosurgery. Neurosurgery 2000;46:1112-1120.

39 J oseph J, A dler JR, Cox RS, H ancock SL: Linear accelerator-based stereotaxic radiosurgery for brain metastases: The influence of number of lesions on survival. J Clin O ncol 1996;14:1085-1092.

\title{
1st Symposium of the
}

\section{International Society for Chemosensitivity Testing in Oncology ISCO}

\author{
September 14 -15, 2001 \\ Homburg/Saar, Germany
}

Information:

Prof. Dr. med. U. Reinhold

Department of Dermatology

The Saarland University Hospital

D-66421 Homburg/Saar

Tel. +49 684116 38-32, Fax - 45

E-mail hadneu@med-rz.uni-sb.de 